\title{
AN EXPERIMENT IN CLASSIFYING PRIMARY GRADE CHILDREN BY MENTAL AGE.
}

\author{
Bx Frañes LoWELL, PH I \\ TlePaul Unvelaty
}

Purpose Juring the school year beginning September 17th, 1920, the writer, as psychologist for the public schoois of Rochester, New York, conducted an experument in the City Normal School to determine the advisablit of classifying children in the first, second and thurd grades on the basis of mental, rather than chronological, age

Conditions. The conditions for experimentation were as neatly perfect as one may hope to find in any public school system. Becucse of 112 hear co-operition of the principal, teachers, and school nurse, and because the school used was connected with a City Normal School, the experimenter had absolute freedom in making any desired changes $m$ placing of children, in using all school and health records, and in securing physical examinations of children with presumably remediable defects.

Orignal Organzation of Primary Grades. The general plan of primary organization in the Normal School, as it existed in September, provided each grade, with one exception, with four classes. These classes consisted of two B sections and two A sections. The B sections were beginning first grade work; the A sections had finished one semester. Within each of these B and A groups, a further differentiation was made into average and slow divisions. Tnese nere designated by the use of the Arabic numerals 1 and 2 placed after the section letter. Thus, the average First $B$ class " vald be designated IB1, and the slow First B by IB2, the aveiage Fin st $A$ class would be indicared at IA1, and the slow First $A$ as IA2: the average fecond B yrade as IIB1, and the slow Second B is IIB2, etc The average classes were composed of the childien who were expected to accomplish the work of their grade satisfactorily, regardless of their chronological ages. The slow groups consisted of children whom the teachers considered too slow in comprehension to succeed in the average group, but too capable mentally to be placed in special classes for subnormals. The exception, mentioned above, to having an average and a slow division for each section of a grade, was in the First A grade, where limited space made it necessary to have just one room accommodating fifty children on half day sessions. The total enrollment in September of the First, Second, and Third Grades was about 300 , besides a kindergarten to draw from, which averaged 175 children.

In addition to these average and slow classes, there was a small 
group of "problem" cases, known as the "Observation Class" Originally, this group had been composed of about ten children from the first three grades, who either had been absent for several weeks and on their return were found to be in need of special help if they were to continue successfully the work of their grades; or who had some special disability, and after a few weeks in school were found to need more individual attention and help in some subject than the regular teacher could give These children and others having similiar difficulties, were observed carefully and given the necessary ald and encouragement by a teacher tramed in ungraded work Eventually, they returned to then regulul giades and others took theil places However, this class had become a "dumpingground" for all kinds of misfits-mental, social and physical-of the first three grades. In September, it consisted of nine such misfit cases, who were being instructed by a teacher without any speciai traming in the wolk, and who were making little progres because of the mability of the teacher to deal with the large varıety of disabilitie: exhibited by the different members of the group. At the mid-year reolganization of the grades, to be described later, this class was abolished

Mental Eaamination in Fust Grades After having carefully surveyed the conditions existing in the first three grades, the writel gave individual mental examinations to the children. The Kuhlmann Revision of the Binet Tests* was used throughout the experiment for obtaining the mental ages of the pupils. The "Observation Class" and all First Grade chldren were examined before the mid-year promotions occurred The results of these examinations as obtained from each class, pefore any changes in grading had been made by the write1, are shown in the following tables

Table I gives for each grade the average chronological age and the distribution of cases according to chronological age, Table II mdicates the average mental age and the distribution of cases by mental age in each grade, and Table III siow, the average intelligence quotient and the distribution of intelligence quotients by grades before reorganization.

"Kuhlmann, F A Handbook of Mental Tests 1922 
TABLE I

1)istiıbution by Chronological Ages Before Reorganization

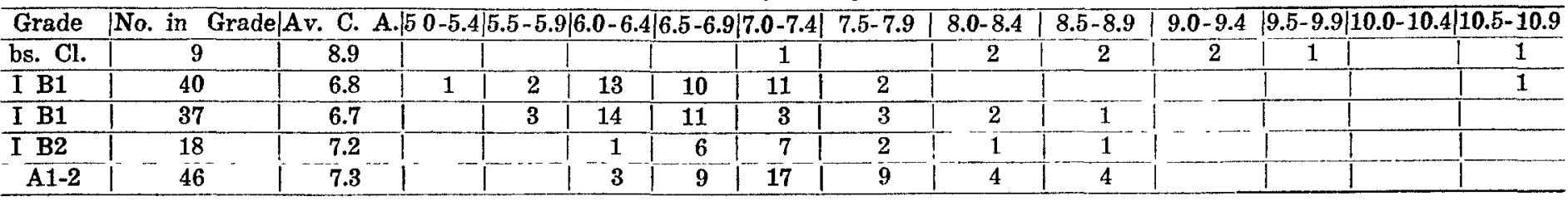

TABLE II

1)istiubution by Mental Ages.

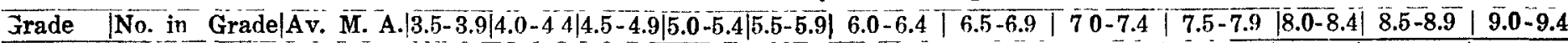
bs. Cl.

I B1

I B1

I B2

A 1-2

\begin{tabular}{l|l}
\hline 9 & \\
\hline 40 & \\
37 & \\
18 & \\
\hline 46 &
\end{tabular}

\begin{tabular}{|l|l|l|l|l|}
\hline 7.1 & & & & \\
\hline 6.4 & 1 & & 2 & \\
\hline 6.4 & & 1 & & 2 \\
\hline 6.2 & & & 1 & 1 \\
\hline 7.1 & & & & \\
\hline
\end{tabular}

\begin{tabular}{|c|c|}
\hline 3 & 2 \\
\hline 4 & 18 \\
\hline 3 & 8 \\
\hline & 8 \\
\hline
\end{tabular}

$\begin{array}{r}3 \\ \hline 13 \\ \hline 3 \\ \hline 15\end{array}$

TABLE III

Distisbution by Intelligence Quoisents

\begin{tabular}{|c|c|c|c|c|}
\hline 2 & & 1 & 1 & \\
\hline 5 & -1 & 1 & 1 & \\
\hline 6 & 1 & & & \\
\hline 11 & 5 & 3 & 3 & 1 \\
\hline
\end{tabular}

Grade $\mid$ No. in Grade|Av. I. Q.| $50-.59|.60-.69| .70-.79|.80-.89| .90-.99|1.00-1.09| 110-1.19|1.20-1.29| \overline{1.30-1.39} \mid$ Jbs. Cl. I

I B1

I B1

I B2

\begin{tabular}{|c|c|c|c|}
\hline 9 & .80 & & \\
\hline 40 & .95 & 1 & 2 \\
\hline 37 & .96 & & 2 \\
\hline 18 & .87 & & 2 \\
\hline 46 & .98 & & \\
\hline
\end{tabular}

\begin{tabular}{r|}
5 \\
2 \\
\hline 1 \\
\hline 2 \\
\hline 4 \\
\hline
\end{tabular}

\begin{tabular}{|r|r|}
$\mid$ & 2 \\
\hline 17 & \\
\hline 14 & \\
\hline 16 &
\end{tabular}

\begin{tabular}{|c|}
\hline 7 \\
\hline 9 \\
\hline 2 \\
\hline 12 \\
\hline
\end{tabular}

$\left|\begin{array}{|c|}\mid \\ \mid \\ \mid \\ 4\end{array}\right|$

$\mid$

$\frac{39 \mid}{1}+\frac{1}{1}$


It will be noticed that each table shows two sections of average First B Grade children, 1. e., of IB1. This 1s due to the fact that, in September, the number of children entering the first grade is too large to be accommodated in one room and hence two sections are needed In the two IB1 groups there were thirteen children who had not yet attained a mental age of six, and nineteen whose intelligence quotients were below .90 Only six children of these groups were below 6 years chronologically, and these were all superior cases

The slow or IDZ group had frve cases with mental ages less than 6 years Although the slow class was supposed to contam only children with mierion intelligence, or more specifically, dull but not feebleminded chilirer, this ciass had eight cases who were normal or superior, and four who were feebleminded

'The IA grade shuwed childwen ranging in isental age fror" "to $9 \%$ years. While it is generally conceded that a $61 / 2$ year ment is necessary for vaccesful $1 \mathrm{~A}$ work, elght chldien in the group were below that age mentally, and eleven had intelligence quotients below .90 .

Reorganization of Frrst Grades at Mid-year. By the time all of tise first gracies had been cested, it was time for the mid-year promotions, and so the writer made the necessary adjustments in placing at that time The results of these adyustments are summarized in Tables IV-VI. In considering these tatules it must be remembered that the "Observation Class" was abolished, and a class of repeating IB children given to the teachel Although in January these repeaters all tested over 6 years mentally; and had intelligence quocients above .90 , thirteen of them had fasled to make ther grade because of mental mmaturity. Table $V$ shows tliat these thirteen children, after five montis of IB work, had attained a mental age of only 6 to $6 \%$ years. When they entejed the grade in September, tiley must, therefore, have been less than six years mentally. The fallures of the other five children in the class were due either to their inability to work successfully in a large group, or to long absences from school. This gloup of repeatels is designaied in Tables IV-VI as IE2. The othe IB1 group= of the first semester became IA1 at the mi-year pronotion time, and the slow 1B2 became 1A2 The old IA1-2 section was drvided and promoted to IIB1 and IIB2 according as the intelligence quoilents of the undividuals were atove or below 90. From the Kindergarten comes a new group of IB1 and a new one of IB3 children, all of whom were mentally examined by the v'riter and found to have a montal age of at least 6 years. Those having intelingence quotients above 90 were 
placed in IB1, and those with intelligence quotients below 90 weie placed in the slow group, namely in IBs

Table IV gives the average chronological age and the distribution of cases according to chronological age for each grade, Table $V$ presents the average mental age and the distribution by mental ages; and Table VI shows the average intelligence cuoticnt and the distribution of cases hy intelligence quotients

Lonble Promotions. It is evident, from an examination of Table $V$, that the re-classification of First Grade pupils was not made, in all cases at least, on a strictly mental-age basis For instance in the newly formed IB1 and IB3 groups, there were eleven childien who had a mental age of $6 \frac{1}{2}$ years or over, which is the mental age required for successful work $n$ the IA grade A ingld mental-age classification would have allowed these children either to skip the IB class or to do double work therein, 1 e., to do the work of the IB and the IA grades in one semester However, it seemed more advis able to the writes, to accustom them to the routine of school infe, afier the fieedom of the kindergarten, before permitting them to compete with chldren already habituated-as would be the case if they skipped the IB class--or before allowing them to attempt the extra work involvd in double promotions In the case of the five, mentally over-age, IB2 1epeaters, who could not work successfully in lirge 2roups it seemed desirable to place them 11, a small grout. of children whuse mental ages were slightly lowel, in order that thelr greater abllity might aid them in gaining some much needed self-confidence. Hence the same requirements were made of all IB children iegardless of whether they were average or superior mentally.

In the IA1 groups there were eleven chldren whose mental ages would warrant their being placed in a second grade. Instead of being allowed to skip the IA class, these chıldren were given an opportunity to complete the work of the IA and IIB grades in one semester. Since, for efficient handling of groups, each teacher divided her room into three sections, it was a simple matter to put the chldren who had mental ages over $6 \frac{1 / 2}{1}$ years into a little group by themselves, and allow them to take the work as rapidly as they were able. To make sure, towards the end of the semester, that the standards of the IIB grade were adhered to, these children were occasionally sent in to share an arithmetic or reading lesson with the regular second grade children. In June, all of these pupils of superior mentality were given double promotions from IA1 to IIA1, since they had completed both IA1 and IIB1 work in one semester. Most of these children aite the double promotion, would be working in a grade suited to their mental ability 


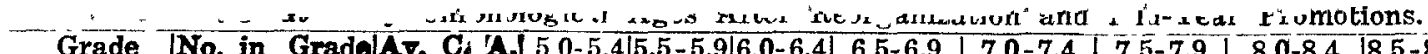

\begin{tabular}{|c|c|c|c|c|c|c|c|c|c|c|c|}
\hline Grade & No. in & Grade|Av. Ci & A. $50-5$. & $4 \mid 5.5-5$. & |6.0-6.4 & $6.5-6.9$ & $7.0-7.4$ & $7.5-7.9$ & $8.0-8.4$ & $\overline{8.5}-8.9$ & $9[9.0-9.4$ \\
\hline I B1 & 31 & 58 & 2 & 17 & 8 & 3 & 1 & & & & \\
\hline I B2 & 18 & 62 & & 1 & 12 & 4 & 1 & & & & \\
\hline I B3 & 16 & 7.2 & & & & 3 & $\overline{5}$ & 6 & 2 & & \\
\hline I A1 & 22 & 6.7 & & 3 & 4 & 10 & 3 & 2 & & & \\
\hline I A1 & 22 & 6.6 & 1. & 1 & 8 & 8 & 4 & & & & \\
\hline $\mathbf{I} \overrightarrow{\mathbf{A}} \overrightarrow{\mathbf{2}}$ & 11 & $7 . \overline{2}$ & & & & & 5 & 1 & 2 & 3 & \\
\hline II $\mathrm{B} 1$ & 25 & 7.3 & & & 1 & 4 & 10 & 6 & 4 & & \\
\hline II $\overline{\mathrm{B} 2}$ & 18 & 8.3 & & & & & 1 & 4 & 7 & 4 & 2 \\
\hline
\end{tabular}

\section{TABLE V}

Distribution by Mental Ages

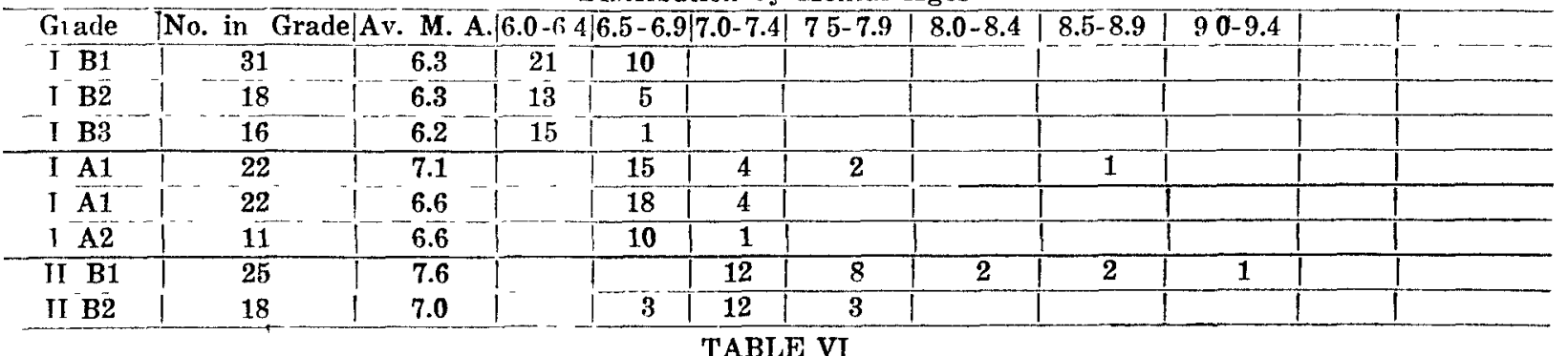

Distı 1 bution by Intelligence Quotients.

Grade $\mid$ No. in Grade $\mid$ Ave. I. Q $|70-79| \overline{70-.89|.90-.99| 1.00-1.09|1.10-1.19| 1.20-1.29|1.30-1.39|}$

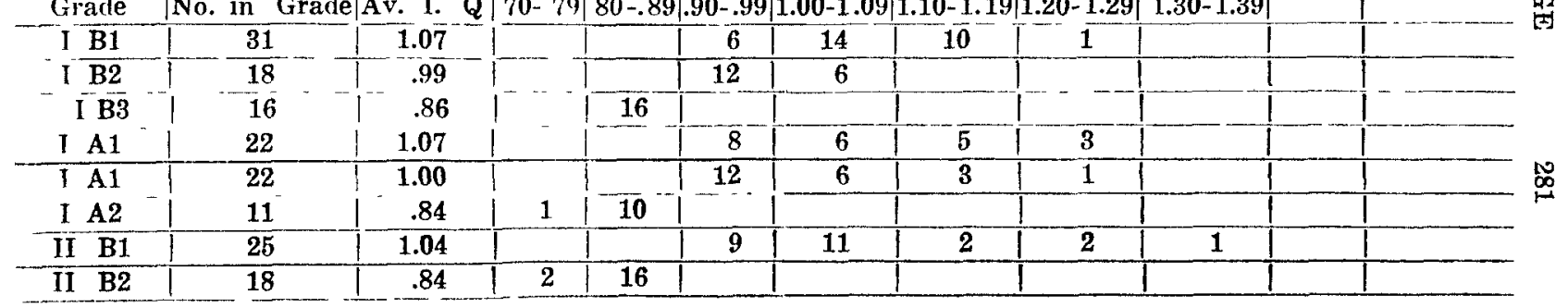


The same conditions exisied in the IIB grade, and the superiol childien were given double piomotions in June from the IiB1 to the IIIB1. as they had completed the vork of both the IIBI and the IIA1 grades in the one imesiel

Although, as stated above, the wiltel employed a double promotion method, and regards it as the method, unde the existing conditions, best suited to the primary grades to bing about adaptation between school grades and the mental ability of children, she does not wish to be regarded as giving it an unqualified endorsement Double promotions shonid probahly not be continued beyond the fourth gade, because such a course would result in children finishing the grades long before they were physically or socially read to mingle whll high school students

Dernotions In the IB grade, twelve chlddren were found whose mental ages, at the mid-yeai, were les- tian 6 yeals Tnese vere demoted to the kindergarten, though some of them had repeated IB work two and even three times The joy of finding something in school that they could actually do, compensated for ther falure to complete the IB work at that time The parents of only two of these childien inquired about the demotion, and to these the witer explained that the children had become so discouraged over their inability to do what the other pupils wore doing that they had ceased even to make an effort; that wlule they were chronologically old enough for first grade, then minds were still too immature for it; that by placing them in the kindergarten for a little while longer, where they could do the work, and in fact, be leaders, their self-confidence would be restored to such an extent that when they later were mentally ready for the first grade, they could do the work and do it well.

The writer is convinced that when children have spent the allotted two years in the kundergarten, and stlll are not ready mentally to undertake first grade work, provision should be made fri: a "pre-primer" class. This should be a sort of preparatory class in which work more advanced than that of the kindergarten, but less difficult than that of the first grade, should be given Much physical training and language work might well be the basis for a course of this kind. The need for a "pre-primer" class is strongly felt in cases where children are overdeveloped physically hut underdeveloped mentally, and yet are too young to be placed in a special class for the feebleminded

Mental Exammations in Second and Thurd Grades Duıng the second semester, from January to June, the writer gave individual mental examinations to the chldren in the remaining 
TABLE VII

Distribution by Chronological Ages Before Reorganization.

\begin{tabular}{|c|c|c|c|c|c|c|c|c|c|c|c|}
\hline Grade & No. in Grade & $\overline{A v}, \bar{C} . \bar{A}$ & $\bar{A} . \mid 6.5-6.9$ & $9 \mid 7.0-7.4$ & $|7.5-7.9|$ & $8.0-8.4$ & $8.5-8.9$ & $9.0-94$ & $9.5-99$ & $|10.0-10.4| 10.5-10.9$ & $111.0-11.4$ \\
\hline II $\overline{A 1}$ & 37 & 8.0 & 3 & 5 & 11 & 10 & 3 & 3 & 2 & $1 \quad-1$ & \\
\hline II A2 & 26 & 8.4 & & & 5 & 10 & 5 & 4 & & 2 & \\
\hline III $\mathbf{B 2}$ & 24 & 9.5 & & & & 4 & 5 & 1 & 5 & 8 & 1 \\
\hline
\end{tabular}

\section{TABLE VIII}

Distribution by Mental Ages

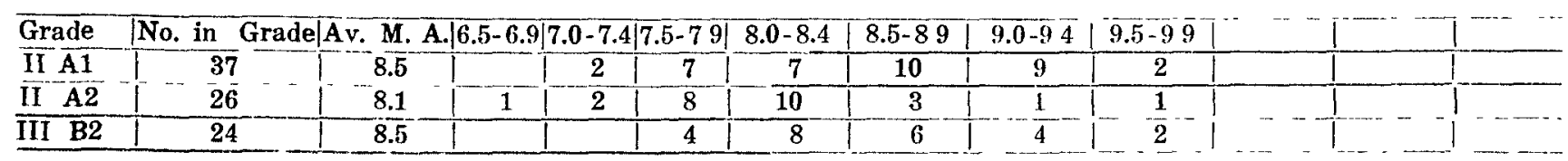

TABLE 1X

Distribution by Intelligence Quotients

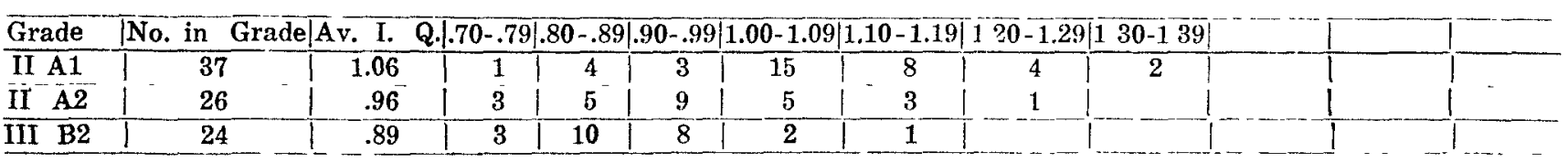


sections of the second grade, 1 e., to the IIA1 and the IIA2 and to the slow section of the IIIB grade.

Table VII gives for each grade the average chronological age, and the distribution of cases according to chronological age Table VIII show's the average mental age and the distribution by mental age for each grade, and Table IX gives the average intelligence quotient and the distribution by intelligence quotients per grade

Inspection of Table VIII shows that twenty-eight of the thurty-seven children in the IIA1 grade had a mental age of 8 years or over, which is the mental age required of third grade children. Even in the slow IIA, more than one-half of the pupils possessed thrrd grade mentality In the slow IIIB class, sIx children were mentally ready for the fourth grade The distribution of cases by intelligence quotients is still more interesting Table IX shows that in both the IIA1 and the IIA2 groups, the range of quotients is from 70 to 140 or, in terms of brightness, from feeblemindedness to "near genuus"; while in the slow IIIB group, it is from .70 to 1.20 , or from feeblemindedness to a high degree of superiority.

It was nearing the end of May when these exammations were completed, so the changes in classification were not made until the time for June promotions Tables X - XII represent the organization of these groups as it existed at the end of the school yeas, after a classification by mental age had been made by the writer. They show, for each grade, the distribution of cases according to chronological age, mental age and intelligence quotients, respectuvely.

Reorganization of Second and Third Grades in June. In reorganuzing these groups, mental age again formed the basis for selection, and where possible, brightness also was considered. In selecting children for the two sections of IIIB1, it was necessary to remember that the purposes of the groups were different. The first section was to be composed of children whose mental ages were, or would be by September, sufficiently high, and whose intelligence quotients indicated brightness of such a degree, that the chlddren would be capable of doing double work, that is, the work of both the IIIB and the IIIA grades, in one semester. The second section of the IIIB1 would do only the regular IIIB wolk during the term. With this in mind, the writer selected for the first section thurty-three chlldren whose average mental age was 9.1 years, and whose average intelligence quotient was 111 . It will be noted, however, that seieral superior children were placed in the second section of the IIIB1, while 
TABLE X

Distribution by Chronological Ages After Reorganization.

\begin{tabular}{|c|c|c|c|c|c|c|c|c|c|c|}
\hline Grade & No. in Grade & Av. C. A. & $|7.0-7.4|$ & $7.5-7.9$ & $|8.0-8.4|$ & $8.5-8.9$ & $9.0-9.4$ & $9.5-9.9$ & $10.0-10.4$ & $10.5-10.9$ \\
\hline III B1 & 33 & 8.3 & 3 & 5 & 16 & 7 & 2 & & & \\
\hline III B1 & 18 & 8.3 & & 5 & 5 & 6 & 2 & & & \\
\hline III B2 & 16 & 9.5 & 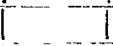 & & & 3 & 5 & 5 & 2 & 1 \\
\hline III $\mathrm{A2}$ & 18 & 10.0 & & & & 2 & 3 & 3 & 4 & 6 \\
\hline 空 & & & Distri & $\begin{array}{r}\text { TA } \\
\text { ibution }\end{array}$ & $\begin{array}{l}\text { BLE X } \\
\text { by Mer }\end{array}$ & II Age & & & & \\
\hline Grade & No. in Grade & Av. M. A. & $7.5-7.9$ & $8.0-8.4$ & $8.5-8.9$ & $9.0-9.4$ & $9.5-9.9$ & $10.0-10.4$ & $10.5-10.9$ & \\
\hline III $\mathrm{B1}$ & 33 & 9.1 & & 4 & 9 & 9 & 8 & 2 & 1 & \\
\hline III B1 & 18 & 8.6 & & 9 & 7 & 2 & & & & \\
\hline III $\mathbf{B 2}$ & 16 & 8.2 & 1 & 12 & 3 & & & & & \\
\hline III A2 & 18 & 8.6 & 1 & 8 & 3 & 6 & & & & \\
\hline 8 & & & Istributi & $\begin{array}{r}\text { TAI } \\
\text { ion by } I\end{array}$ & $\begin{array}{l}\text { BLE XI } \\
\text { Intellige }\end{array}$ & $\begin{array}{l}\text { II } \\
\text { ence Quot }\end{array}$ & ients. & & & \\
\hline Grade & No. in Grade & Av. I. Q. & $|.70-.79|$ & $|.80-.89|$ & $\mid .90-.99$ & $1.00-1.09$ & $|1.10-1.19|$ & $\mid 1.20-1.29$ & $\mid 1.30-1.39$ & \\
\hline III $\mathrm{B1}$ & 33 & 1.11 & & & 2 & 13 & 12 & 4 & 2 & \\
\hline$\overline{\text { III }} \mathrm{B1}$ & 18 & 1.04 & & & 5 & 10 & 2 & 1 & & \\
\hline III B2 & 16 & .87 & 2 & 9 & 5 & & & & & \\
\hline III $\overline{\mathbf{A 2}}$ & 18 & 87 & 1 & 11 & 6 & & & & & \\
\hline
\end{tabular}


several average children were included in the first sectıon. This was due to the fact that the superior children mentioned had been absent for several weeks with whooping cough, and whlle it was thought probable that they could overcome this handicap sufficiently to be given a single promotion, it did not seem advisable to allow them to be doubly promoted. Consequently, the first section of the IIIB1 had to be completed by a few children of average abilty who possessed, in adtition to the mental age necessary for the work, excellent health, 1emalkable pers!stence and fine habits of study

Furthel consideration of Tables X - XII brings out certain facts regarding the two slow groups IIIB2 and IIIA2. While the difference in the average mental age of these two groups is approximately one-half year, yet the distribution of cases according to mental age shows but shght varation in the two groups In fact, half of the IIIA2 pupils possess mental ages which, under ordmary conditions, would indicate that they belong in the IIIB2 group, i. e., they possess 8 year instead of $8 \frac{1}{2}$ year mental abllity. Why, then, it will be asked, were they placed in the IIIA2 class along with children who really possess third A mentality? Because they had already repeated the IIIB2 grade twice! Advanceing these chldren to a higher grade with its new interests was the only existing alternative to forcing them, for a fourth time, through the routine of the hated IIIB2.

Although many school systems are providing special courses of study for theil feebleminded and superior children, few have yet arranged a special curriculm for their slow, dull children. In the first and second grades. it is largely a matter of time before the dull child can accomplish, in some fashion, the work required of the average pupil in the same grade, but in the higher grades, it becomes practically impossible for him to master all phases of the work, even when the time is unlimited He keeps repeating grades until he has not only lost all interest in the school work, and ceased to make any effort to learn, but until he has lost his self-confidence, and indeed, even his self-respect. Until schools provide a special curriculm adapted to the needs and limltations of these dull children-children with intelligence quotients from .75 to .89 inclusive-little is to be gained from classifying them on the basis of mental age. And yet, $34 \%$, or more than one third of all the primary grade children in the school used in this study, and it was a representative school, belong to the dull group.

What is the significance of an intelligence quotient of .75? Or more specifically, what is the outlook for such children as those in the IIIA2, whose chronological age is 10.5 years, whose mental 
age is 7.9 years, and whose intelligence quotient, therefore, is $75 \%$ In their $4 \frac{1}{2}$ years of school attendance, assuming that they entered when they were chronologically six, they have completed $21 / 2$ years' work If they continue their school hife until they are 16 years old, at which age the law, in most states, permits them to leave school and go to work, they will have had $51 / 2$ years more of school attendance, which will presumably place them in the VIA grade. At that time their mental age would be 12 years, and the intelligence quotient, of course, would still be about .75 What are these chldren fitted to do when they leave school at the age of 16 years" Nothing' They have been strugghng with arithmetic, history, geography or grammar, instead of acquiring knowledge of practical value Still, school systems do not feel it encumbent upon them to provide a curriculum which will fit the dull child to earn his living and cope with his environment

The changes made in reorganizing the IIIB2 and IIIA2 grades were of two kinds First, some normal children, who had been misplaced $m$ the IIIB2, were removed to average groups; and second, the older and more capable children in the IIIA2 were placed with the repeaters from the IIIB2 Time was too brief to permit any examination to be made in the IIIAI grade.

Mental Examination of Kindergarten Pupls During the last month of school, all kindergarten teachers, in the Normal School, reported the names of the kindergarten children who would be ready, chronologically, for entrance into the first grade, in September To these, the writer gave individual mental exammations. The group totalled fifty-seven cases which were disposed of as rollow's

44 - Promoted to IB1 or IB2.

1 - Sent to Institutions for Feebleminded.

1 - Sent to Primary Special Class for Subnormals.

11 - Retained in Kindergarten because they would not be mentally 6 years by September.

The results of the examinations of the forty-four kndergarten children who were promoted in June, 1921, to the IB1 and IB2 grades are presented in Tables XIII $-X V$. Table XIII shows the distribution of cases by chronological age; Table XIV gives the distribution by mental age; and Table $\mathrm{XV}$ by intelligence quotrents

Effect of Mental-Auc Classification on Promotions A careful study of dats, obtamed from an experiment sucl as the one discussed in this papel, bings forth a very practical question If children $a^{2} e$ gladed according to mental age, wll retardation in scrosh be o-sul', seduced" In other wouds, wll the percentage 
TABLE XIII

Listribution by Chronological Ages.

\begin{tabular}{c|c|c|c|c|c|c|c|c|c|c|c|c|}
\hline Grade & No. in & Grade & Av. C. A. & $5.0-5.4$ & $5.5-5.9$ & $6.0-6.4$ & $6.5-6.9$ & $7.0-7$ & $4.5-7.9$ & $8.0-8.4$ \\
\hline I B1 & 32 & 5.9 & 3 & 16 & 11 & 1 & 1 & \\
\hline I B2 & 12 & 6.9 & & & 2 & 4 & 4 & 1 & 1 \\
\hline
\end{tabular}

TABLE XIV

Distribution by Mental Ages.

\begin{tabular}{c|c|c|c|c|c|c|c|c|c|}
\hline Grade & |No. in & Grade|Av. M. A. $5.5-5.9$ & $6.0-6.4$ & $6.5-6.9$ & $7.0-7.4$ & & \\
\hline I B1 & 32 & 6.4 & 2 & 14 & 14 & 2 & & \\
\hline I B2 & 12 & 6.1 & 4 & 7 & 1 & & & \\
\hline
\end{tabular}

TABLE XV

Distribution by Intelligence Quotients.

\begin{tabular}{c|c|c|c|c|c|c|c|c|c|c|c|c|}
\hline Grade & No. in & Grade|Av. I. & Q. & .70 & -.79 & .80 & -89 & .90 & -.99 & $1.00-1.09$ & $1.10-1.19$ & $1.20-1.29$ \\
\hline I B1 & 32 & 1.09 & & & 3 & 16 & 10 & 3 & \\
\hline I B2 & 12 & .88 & 1 & 5 & 6 & & & \\
\hline
\end{tabular}


of honestly earned promotions be nearly $100^{\circ}$ A rather convincing answer to that question is given by the records showing the per sentagr v. "Wotion. Ior ti-e first grades of the City Normal School betore the classtication was made and also afterwards These figures represent both slow and average groups combined.

$$
\begin{aligned}
& \text { June } 1920-62^{r} \\
& \text { June } 1921-87 \%
\end{aligned}
$$

If we analyze the percentage of promotions for June, 1921, into its component parts we find a still more convincing reply to our question. Considering just the IB1 and IAI groups, or 66 cases, the percentage of promotions was 97 , and $23 \%$ of these were double promotions Considering just the slow groups, or 41 cases, only $68 \%$ were promoted. Likewise in the IIB1 and IIA1, or 64 cases, there were $100 \%$ promoted. Yet in the slow second grades, i. e., the IIB2 and IIA2, there were only 75\% promoted.

The above data indicate, then, that the average pupll, when placed according to mental age in a grade, will successfully accomplish the work of that grade, since the curriculum is fairly well adapted to the ability of the average child. The dull child, on the other hand, even when placed according to mental age in a grade, will be unable to accomplish the work in the time allotted, because of his slower rate of mental growth Consequently, when no special curriculum is provided for him, he will have to repeat the grade, and the bad habits of study, the loss of interest and of self-respect, the attitude of discouragement and hopelessness which accompany the repetition of a grade, continue to cause further failure, even though at the time of the second trial, there is sufficient mental ability to insure success.

Summary. From the data obtained from this experiment in classifying primary children on the basis of mental age, the following conclusions have been suggested

1. In grades where classification is not based upon mental age, one finds between the children of a single class as great a range in mental age as $5-3 / 8$ years, and in intelligence quotients as great a difference as 79 points, yet these children are all trying to accomplish the same tasks and assimilate the same amount of subject matter

2. Both mental ages and intelligence quotients must be considered in arranging classes. Children may have the same mental ages and yet differ so greatly in chronological ages that it would be impracticable for them to try to work together

3. When mental age and brightness are used as a basis for classification, it is possible to separate the dull and feebleminded children from the average and superior individuals, so that each may com- 
pete with others of his own mental calibre

4 Slow groups should be formed from the first grade up, and a special curriculum worked out which will fit these children to earn a living, since most of them never get beyond the suxth grade.

5. The superior chldren, instead of skipping grades, may be given double work, which will bring them up, in a semester or two, to the grade for which they are mentally ready, without the loss of any fundamental part of the school work.

6. Where first grade work is standardized upon the basis of the performance of average chldren 6 years old chronologically, no child should be allowed to enter the first grade before he has attained a mental age of 6 years. If he is chronologically six, and has been in the kindergarten two years, or if the school system does not provide for kindergarten training, he should be placed in a pre-primer or "preparatory-to-first-grade" class until he becomes 6 years mentally.

7. When the teaching and the curriculum are adequate, and when chldren are not exposed to the work of any grade untll they are mentally qualified for it, a mental age classification will give practically $100 \%$ of promotions in the primary grades. 